\title{
Recurrence of cervical intraepithelial lesions after thermo-coagulation in HIV-positive and HIV-negative Nigerian women
}

Emmanuel A. Oga ${ }^{1,2^{*}}$, Jessica P. Brown ${ }^{1}$, Clayton Brown ${ }^{1}$, Eileen Dareng ${ }^{2,10}$, Victor Adekanmbi ${ }^{2}$, Michael Odutola ${ }^{2}$, Olayinka Olaniyan ${ }^{3}$, Richard Offiong ${ }^{4}$, Kayode Obende ${ }^{5}$, Ayodele Stephen Adewole ${ }^{6}$, Achara Peter ${ }^{7}$, Patrick Dakum $^{2}$ and Clement Adebamowo

\begin{abstract}
Background: The burden of cervical cancer remains huge globally, more so in sub-Saharan Africa. Effectiveness of screening, rates of recurrence following treatment and factors driving these in Africans have not been sufficiently studied. The purpose of this study therefore was to investigate factors associated with recurrence of cervical intraepithelial lesions following thermo-coagulation in HIV-positive and HIV-negative Nigerian women using Visual Inspection with Acetic Acid (VIA) or Lugol's lodine (VILI) for diagnosis.

Methods: A retrospective cohort study was conducted, recruiting participants from the cervical cancer "see and treat" program of IHVN. Data from 6 sites collected over a 4-year period was used. Inclusion criteria were: age $\geq 18$ years, baseline HIV status known, VIA or VILI positive and thermo-coagulation done. Logistic regression was performed to examine the proportion of women with recurrence and to examine factors associated with recurrence.

Results: Out of 177 women included in study, $67.8 \%$ (120/177) were HIV-positive and $32.2 \%$ (57/177) were HIV-negative. Recurrence occurred in $16.4 \%$ (29/177) of participants; this was $18.3 \%(22 / 120)$ in HIV-positive women compared to $12.3 \%$ (7/57) in HIV-negative women but this difference was not statistically significant (p-value 0.31). Women aged $\geq 30$ years were much less likely to develop recurrence, adjusted $\mathrm{OR}=0.34(95 \% \mathrm{Cl}=0.13,0.92)$. Among HIV-positive women, CD4 count $<200 \mathrm{cell} / \mathrm{s} / \mathrm{mm}^{3}$ was associated with recurrence, adjusted OR $=5.47$ (95\% Cl=1.24, 24.18).

Conclusion: Recurrence of VIA or VILI positive lesions after thermo-coagulation occurs in a significant proportion of women. HIV-positive women with low CD4 counts are at increased risk of recurrent lesions and may be related to immunosuppression.
\end{abstract}

Keywords: Cervical Intraepithelial Neoplasia (CIN), Cervical cancer, Visual inspection, Acetic acid, Lugol's lodine, Recurrence, HIV, Thermo-coagulation, Cold coagulation, Ablation, Cervical Intraepithelial lesions, See-and-treat and Nigeria

\footnotetext{
* Correspondence: imanueloga@gmail.com

${ }^{1}$ Department of Epidemiology and Public Health, University of Maryland

School of Medicine, Baltimore, MD 21201, USA

${ }^{2}$ Institute of Human Virology Nigeria (IHVN), Abuja, Nigeria

Full list of author information is available at the end of the article
} 


\section{Background}

Cervical cancer is the fourth most common cancer in women and the fourth most common cause of cancer death worldwide [1]. While its incidence and mortality are falling in the developed world, mainly as a result of widespread adoption of cervical cancer screening covering about $75 \%$ of at-risk women [2-4], in developing countries, where the burden is most severe, the incidence and mortality remain high and screening covers only $5 \%$ of at-risk women $[5,6]$. Cervical cancer is also one of the AIDS defining cancers and several studies suggest that its incidence is higher among HIV positive individuals [7-11]. In Sub-Saharan Africa the prevalence of HIV and cervical cancer are high. In Nigeria, the Age Standardized Incidence Rate (ASR) of cervical cancer was 34.5 per 100,000 in 2011, making it the second most common cancer in the country [12] and there were 3.2 million people living with HIV in 2013 (2nd highest globally) [13].

Cervical cancer occurs after a long asymptomatic premalignant phase, which is referred to as Cervical Intraepithelial Neoplasia (CIN). Majority of low-grade CIN lesions regress and only some high-grade CIN lesions progress to invasive cancer [14]. HIV infection is associated with higher risk of developing CIN; increased risk of developing a higher grade of disease and more rapid progression to malignant disease [15]. Treatment of high grade CIN using excisional or ablative methods are efficacious and substantially reduces risk of cervical cancer however they can be followed by recurrent disease [16].

Thermo-coagulation is an ablative treatment for premalignant lesions of the cervix developed by Kurt Semm in 1966 and is increasingly used worldwide. It uses electricity to generate temperatures of $100-120{ }^{\circ} \mathrm{C}$ for ablation of cervical lesions and can be used for all stages of CIN with minimal side effects. It is also safe, low-cost, has high client acceptance levels and is thus used in combination with visual inspection with acetic acid (VIA) or Lugol's iodine (VILI) in low-resource settings as part of a "see and treat" strategy for cervical cancer screening [17]. Other methods of treating CIN include cryotherapy and excisional methods such as cold knife excision, loop excision of the transformation zone and laser conization.

Recurrence of CIN following treatment occurs in at least $15 \%$ of cases even with the most effective excisional and ablative treatment modalities; and studies suggest that recurrence is associated with immunosuppression, HIV infection, positive endocervical margins, CIN grade, persistent HPV infection, glandular involvement and demographic factors [16, 18-26]. Excisional treatment of cervical lesions is more widely practiced in developed countries while ablative methods like thermocoagulation and cryotherapy have gained ground in developing countries, yet recurrence of cervical lesions following treatment is a global problem, and studies have found ablative treatment to be of similar efficacy as excisional treatment irrespective of whether follow-up is based on histology or visual inspection [17]. Factors associated with recurrence after cervical ablative treatments may differ by populations and the specific method of ablation used [19, 24, 25, 27-29]. The risk of recurrence has been evaluated in developed countries but not so much in Africa which has a higher prevalence of HIV and cervical cancer. Previous African studies have focused on recurrence after treatment with techniques such as cryotherapy, electrocautery, laser cautery, LLETZ or cervical conization and there has been no previous study of recurrence after thermo-coagulation [30-32].

\section{Methods}

We conducted an analysis of de-identified data of women who participated in the cervical cancer "see and treat" program of the Institute of Human Virology Nigeria (IHVN) that was implemented in collaboration with 6 hospitals-National Hospital Abuja (NHA), University of Abuja Teaching Hospital (UATH), Garki Hospital Abuja (GHA), Federal Medical Centre Keffi (FMCK), Aminu

Table 1 Study sites by numbers screened and inclusion of participants

\begin{tabular}{|c|c|c|c|c|c|c|}
\hline & \multicolumn{6}{|l|}{ SITE } \\
\hline & $\mathrm{NHA}, n(\%)$ & UATH, $n(\%)$ & $\mathrm{MCHO}, n(\%)$ & GHA, $n(\%)$ & FMCK, $n(\%)$ & $\mathrm{AKTH}, n(\%)$ \\
\hline SCREENED, 5190 & $1979(38.1)$ & $1792(34.5)$ & $539(10.4)$ & $352(6.8)$ & $393(7.6 \%)$ & $135(2.6)$ \\
\hline HIV Positive $=3212, n(\%)$ & $1563(48.7)$ & $1431(44.6)$ & $15(0.4)$ & $39(1.2)$ & $130(4.0)$ & $35(1.1)$ \\
\hline HIV Negative $=1978, n(\%)$ & $416(21.0)$ & $361(18.3)$ & $524(26.5)$ & $313(15.8)$ & $263(13.3)$ & $100(5.1)$ \\
\hline INCLUDED IN STUDY, 177 & $102(57.6)$ & $48(27.1)$ & $8(4.5)$ & $14(8.0)$ & $5(2.8)$ & $0(0.0)$ \\
\hline HIV Positive = 120, n (\%) & $79(65.8)$ & $38(31.7)$ & $1(0.8)$ & $2(1.7)$ & $0(0.0)$ & $0(0.0)$ \\
\hline HIV Negative $=57, n(\%)$ & $32(40.3)$ & $10(18.5)$ & $7(12.3)$ & $12(21.1)$ & $5(8.8)$ & $0(0.0)$ \\
\hline RECURRENCE, 29 & $13(44.8)$ & $13(44.8)$ & $1(3.5)$ & $2(6.9)$ & $0(0.0)$ & $0(0.0)$ \\
\hline HIV Positive = 22, n (\%) & $12(54.5)$ & $10(45.5)$ & $0(0.0)$ & $0(0.0)$ & $0(0.0)$ & $0(0.0)$ \\
\hline HIV Negative =7, n (\%) & $1(14.3)$ & $3(42.8)$ & $1(14.3)$ & $2(28.6)$ & $0(0.0)$ & $0(0.0)$ \\
\hline
\end{tabular}


Kano Teaching Hospital (AKTH) and Mother and Child Hospital, Ondo (MCHO) -in different parts of Nigeria between 2010 and 2014. We evaluated early recurrence of VIA/VILI positive lesions in women who were previously screened and treated for cervical precancer using VIA/VILI.

Women older than 18 years were seen by trained nurses who obtained informed consent and collected demographic data, sexual behavior history, obstetrics and gynecological history, HIV status and if HIV-positive, time of HIV diagnosis and anti-retroviral treatment history. The nurses collected participants' anthropometric measurements, performed a physical examination and a detailed pelvic examination. During the pelvic examination, they performed VIA and VILI for cervical intraepithelial lesions and those who tested positive were offered treatment by thermo-coagulation if their lesions met specific criteria: complete visualization of acetowhite lesion,

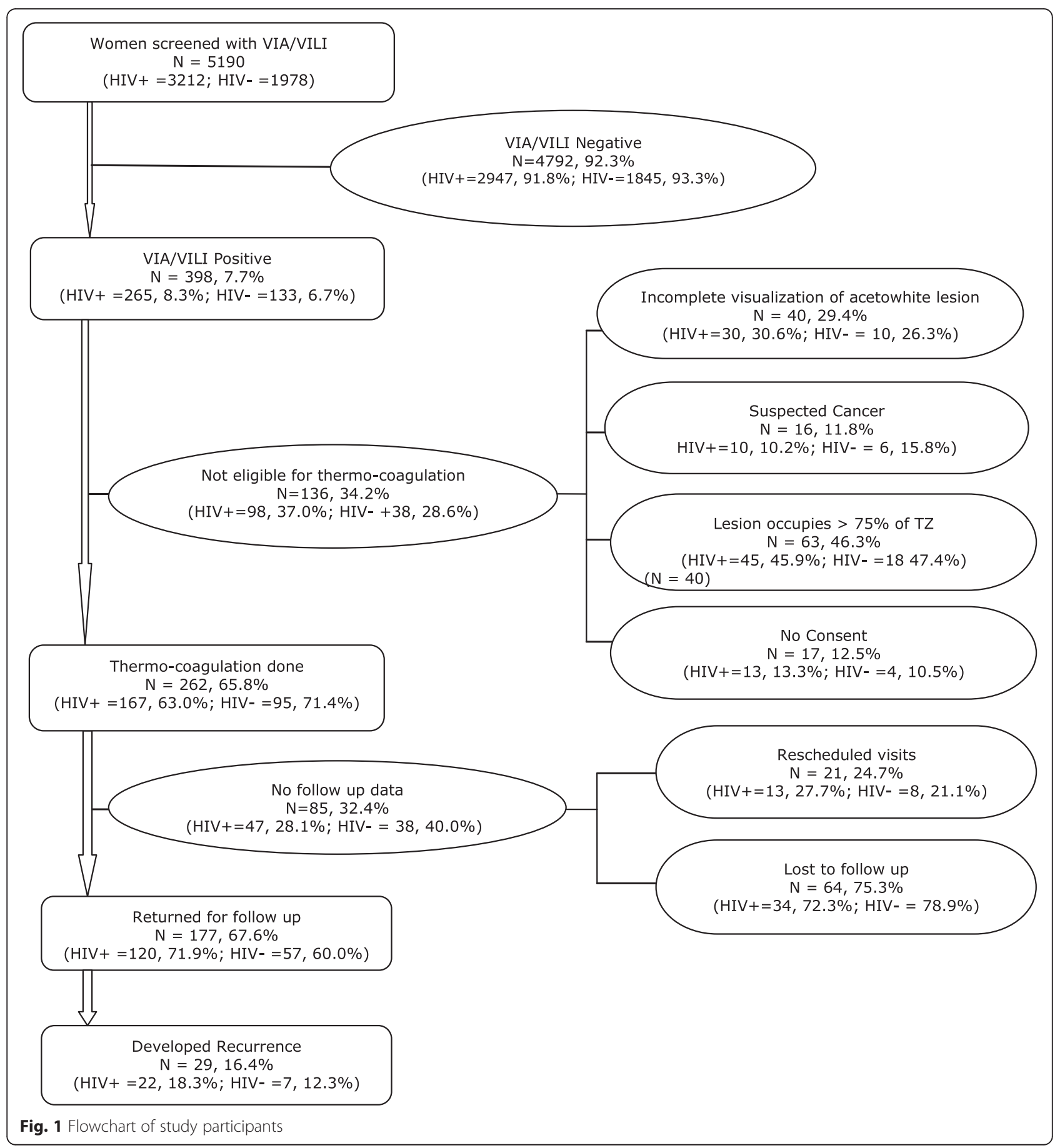


Table 2 Baseline characteristics by HIV status

\begin{tabular}{|c|c|c|c|c|}
\hline Characteristics & & HIV-positive $(N=120) n(\%)$ & HIV-negative $(N=57) n(\%)$ & $P$ value* \\
\hline \multicolumn{5}{|l|}{ Age } \\
\hline$<30$ years & $n(\%)$ & $34.0(28.3)$ & $11.0(19.3)$ & \multirow[t]{2}{*}{0.27} \\
\hline$\geq 30$ years & $n(\%)$ & $86.0(71.7)$ & $46.0(80.7)$ & \\
\hline \multicolumn{5}{|l|}{ Age at first intercourse } \\
\hline$<18$ years & $n(\%)$ & $36.0(30.2)$ & $10.0(18.2)$ & \multirow[t]{2}{*}{0.10} \\
\hline$\geq 18$ years & $n(\%)$ & $83.0(69.8)$ & $45.0(81.8)$ & \\
\hline \multicolumn{5}{|l|}{ Number of Sexual Partners } \\
\hline$\leq 1$ & $n(\%)$ & $97.0(82.2)$ & $48.0(85.7)$ & \multirow[t]{2}{*}{0.67} \\
\hline$>1$ & $n(\%)$ & $21.0(17.8)$ & $8.0(14.3)$ & \\
\hline \multicolumn{5}{|l|}{ Elective Abortions } \\
\hline Ever & $n(\%)$ & $89.0(76.7)$ & $28.0(56.0)$ & \multirow[t]{2}{*}{$0.01^{*}$} \\
\hline Never & $n(\%)$ & $27.0(23.3)$ & $22.0(44.0)$ & \\
\hline \multicolumn{5}{|l|}{ Number of Pregnancies } \\
\hline$<5$ & $n(\%)$ & $84.0(70.6)$ & $30.0(53.6)$ & \multirow[t]{2}{*}{$0.04^{*}$} \\
\hline$\geq 5$ & $n(\%)$ & $35.0(29.4)$ & $26.0(46.4)$ & \\
\hline \multicolumn{5}{|l|}{ Miscarriages } \\
\hline Ever & $n(\%)$ & $9.0(8.3)$ & $11.0(21.6)$ & \multirow[t]{2}{*}{$0.04^{*}$} \\
\hline Never & $n(\%)$ & $99.0(91.7)$ & $40.0(78.4)$ & \\
\hline Body Mass Index (BMI), Mean (SD) & & $24.4(5.2)$ & $28.9(6.5)$ & $0.02^{*}$ \\
\hline \multicolumn{5}{|l|}{ Marital Status } \\
\hline Ever Married & $n(\%)$ & $88.0(73.3)$ & $47.0(82.5)$ & \multirow[t]{2}{*}{0.26} \\
\hline Never Married & $n(\%)$ & $32.0(26.7)$ & $10.0(17.5)$ & \\
\hline \multicolumn{5}{|l|}{ Highest Education } \\
\hline Post-secondary & $n(\%)$ & $52.0(43.7)$ & $36.0(63.2)$ & \multirow[t]{2}{*}{$0.02^{*}$} \\
\hline$\leq$ Secondary & $n(\%)$ & $67.0(56.3)$ & $21.0(36.8)$ & \\
\hline \multicolumn{5}{|l|}{ Contraceptive use } \\
\hline Ever & $n(\%)$ & $51.0(42.5)$ & $35.0(61.4)$ & \multirow[t]{2}{*}{$0.02^{*}$} \\
\hline Never & $n(\%)$ & $69.0(57.5)$ & $22.0(38.6)$ & \\
\hline \multicolumn{5}{|l|}{ Genital Lesions (Warts, Sores or Ulcers) } \\
\hline Yes & $n(\%)$ & $9(40.9)$ & $5(14.7)$ & \multirow[t]{2}{*}{0.06} \\
\hline No & $n(\%)$ & $13(59.1)$ & $29(85.3)$ & \\
\hline Follow up duration in days, Median (Interquartile Range) ${ }^{a}$ & & $793.5(758.0)$ & $371.0(274.0)$ & $<.0001^{*}$ \\
\hline Losses to follow-up & $n(\%)$ & $47.0(28.1)$ & $38.0(40.0)$ & 0.06 \\
\hline \multicolumn{5}{|l|}{ CD4 Count (cells $/ \mathrm{mm}^{3}$ ) } \\
\hline$<200$ & $n(\%)$ & $22.0(23.7)$ & - & \\
\hline$\geq 200$ & $n(\%)$ & $71.0(76.3)$ & & \\
\hline \multicolumn{5}{|l|}{ HAART use } \\
\hline Yes & $n(\%)$ & $105.0(87.5 \%)$ & - & \\
\hline No & $n(\%)$ & $15.0(12.5 \%)$ & & \\
\hline \multicolumn{5}{|l|}{ HAART REGIMEN } \\
\hline AZT-3TC-NVP & $n(\%)$ & $49(53.26)$ & - & \\
\hline EFV-TDF-3TC & $n(\%)$ & $18(19.57)$ & & \\
\hline NVP-TDF-3TC & $n(\%)$ & $7(7.61)$ & & \\
\hline AZT-3TC-EFV & $n(\%)$ & $4(4.35)$ & & \\
\hline
\end{tabular}


Table 2 Baseline characteristics by HIV status (Continued)

\begin{tabular}{lll}
\hline LPV/r-TDF-3TC & $n(\%)$ & $4(4.35)$ \\
TDF-FTC-EFV & $n(\%)$ & $4(4.35)$ \\
AZT-3TC-LPV/r & $n(\%)$ & $2(2.17)$ \\
D4T-3TC-NVP & $n(\%)$ & $2(2.17)$ \\
TDF-FTC-NVP & $n(\%)$ & $2(2.17)$ \\
\hline
\end{tabular}

AZT Zidovudine, 3TC Lamivudine, NVP Nevirapine, EFV Efavirenz, TDF Tenofovir, LPV/r Lopinavir/Ritonavir, FTC Emtricitabine, D4T Stavudine

* Statistically significant at 0.05 level

${ }^{a}$ Comparison of medians was done using Wilcoxon rank-sum test

acetowhite lesion occupying less than 3 quadrants or less than $75 \%$ of the transformation zone, acetowhite lesion amenable to complete coverage by the tip of the cryoprobe, potential to achieve full contact between acetowhite lesion/transformation zone and the cervical probe; and no suspicion of cancer [33, 34]. Participants were followed up at 6-monthly intervals and monitored for recurrence. Women who did not return for their follow up appointments were contacted by telephone to schedule a visit for follow up examinations including evaluation for recurrence of VIA/VILI positive lesions.

Student's $t$-test was used to compare continuous variables between HIV-positive and HIV-negative women while Fisher's exact test was used for categorical variables. Logistic regression was performed to examine the proportion of women with recurrence and to examine factors associated with recurrence. Results are presented with $95 \%$ confidence intervals. Analysis of the recurrence of cervical intraepithelial lesions was limited to women with at least 1 follow-up visit after thermo-coagulation. Multivariable logistic regression was used to identify risk factors for recurrence of cervical intraepithelial lesions. The following variables were evaluated for association with recurrent lesions - age, age at first intercourse, number of elective abortions, pregnancies and number of miscarriages, number of sexual partners, contraception use and CD 4 count. Covariates with $p$ value less than 0.10 , along with biologically relevant variables, were included in the final multivariable model in which $p$ value of less than 0.05 was considered statistically significant. Statistical analyses were performed using $\mathrm{SAS}^{\bullet}$ software (version 9.3).

\section{Results}

Out of a total of 5190 women screened by VIA or VILI over a 4-year period, the proportion of VIA/VILI positive lesions was $7.7 \%(398 / 5190)$; this was $8.3 \%(265 / 3212)$ for HIV-positive women and $6.7 \%$ (133/1978) for HIVnegative women ( $p$-value 0.05 ), see Table 1 and Fig. 1. Among women who were VIA/VILI positive, $65.8 \%$ (262/398) had thermo-coagulation; of the remaining 136 (34.2\%), 109 (80.1\%) were ineligible for thermocoagulation and subsequently referred to a gynecologist, 40 (29.4 \%) had poorly visualized lesions, 16 (11.8\%) had suspected cancer, 63 (46.3\%) had lesions occupying more than three quarters of the transformation zone and $17(12.5 \%)$ did not consent. Note that the participants may have had more than one reason that made them ineligible for treatment by thermo-coagulation. Of those treated, $67.6 \%(177 / 262)$ were followed up for at least 6 months (Fig. 1) and $32.4 \%(85 / 262)$ were lost to followup. Fewer HIV-positive women, $28.1 \%$ (47/167) compared to $40 \%(38 / 95)$ of HIV-negative women ( $p$-value 0.06$)$ were lost to follow-up.

A total of 177 participants who had follow up visit at 6 months were included in the analysis of determinants of recurrent lesions after VIA/VILI and their baseline characteristics are shown in Table 2. The mean age (SD) of these participants was 34.9 (7.4) years and median follow up time was 531 days (IQR $=673)$. Most of these participants, $67.8 \%$ (120/177), were HIV-positive and $32.2 \%$ (57/177) were HIV-negative. Recurrence occurred in $16.4 \%(29 / 177)$ and this was $18.3 \%(22 / 120)$ in HIV-positive women compared to $12.3 \%(7 / 57)$ in HIV-negative women but this difference was not statistically significant ( $p$-value 0.31 ), see Table 3 . Women aged 30 years or older were much less likely to develop recurrence, adjusted $\mathrm{OR}=0.34$ (95\% CI $=0.13,0.92)$. Among HIV-positive women, CD4 cell count $<200$ cells $/ \mathrm{mm} 3$ was associated with recurrence, adjusted OR $=5.47(95 \% \mathrm{CI}=$ 1.24, 24.18) (Table 4).

\section{Discussion}

In this study from Sub-Saharan Africa to evaluate efficacy of thermo-coagulation treatment for VIA/VILI positive cervical lesions, we found that one in six women had a recurrent lesion after treatment and no statistically significant difference existed between recurrence in HIV-positive women compared to HIV-negative women. We also found that women 30 years of age and older were much less likely to develop recurrence and among HIV-positive women, low CD4 count was significantly associated with risk of recurrence. Previous studies have found an association between HIV infection and increased risk of recurrence of CIN following excisional treatment [24, 25, 32].

Our finding that $18.3 \%$ of HIV-positive women in our study had recurrent VIA/VILI positive lesions after 
Table 3 Univariate analysis of factors associated with recurrence $(N=177$; recurrence, $n=29)$

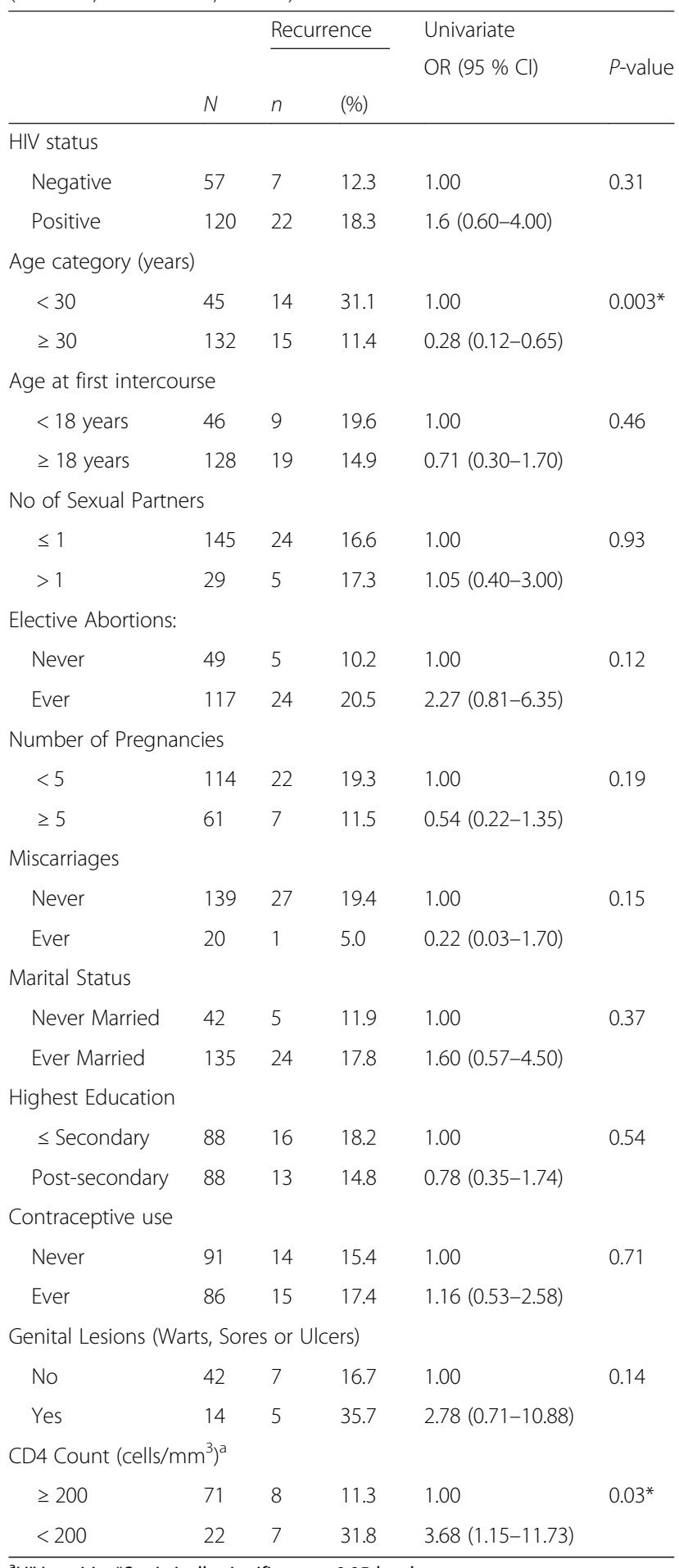

${ }^{a}$ HIV positive*Statistically significant at 0.05 level

treatment compares favorably with a study in Western Kenya that found recurrence in about $13 \%$ of women who have had LLETZ within 12 months of follow up with colposcopy and biopsy [35]. Other studies have reported much higher recurrence in HIV-positive women
Table 4 Multivariable analysis of factors associated with recurrence $(N=177$; recurrence $n=29)$

\begin{tabular}{|c|c|c|}
\hline & Multivariable & \\
\hline & aOR $(95 \%$ Cl) & $P$-value \\
\hline \multicolumn{3}{|l|}{ HIV status } \\
\hline Negative & 1.00 & \multirow[t]{2}{*}{0.97} \\
\hline Positive & $0.98(0.30-3.17)$ & \\
\hline \multicolumn{3}{|c|}{ Age category (years) } \\
\hline$<30$ & 1.00 & \multirow[t]{2}{*}{$0.03^{*}$} \\
\hline$\geq 30$ & $0.34(0.13-0.92)$ & \\
\hline \multicolumn{3}{|c|}{ CD4 Count (cells $/ \mathrm{mm}^{3}$ ) } \\
\hline$\geq 200$ & 1.00 & \multirow[t]{2}{*}{$0.04^{*}$} \\
\hline$<200$ & $5.47(1.24-24.18)$ & \\
\hline
\end{tabular}

following ablative or excisional treatment. Heard et al. [36] reported recurrence of $53.9 \%$ after excisional treatment and follow-up with cytology, colposcopy and histology. Vuyst et al. [37] found recurrence (after follow-up by cytology) of High-grade Squamous Intraepithelial Lesions (HSIL) following cryotherapy to be $22.8 \%$. A systematic review by Tebeu et al. [26] reported recurrence of between 20 and $75 \%$ after excisional treatment and having been followed up by histology; however, studies that utilized ablative treatments like cryotherapy and thermo-coagulation were excluded from analysis.

A few studies have compared recurrence between HIVpositive and HIV-negative women. Fruchter et al. [38] found recurrence to occur in $62.0 \%$ of HIV-positive women compared to $18.0 \%$ of HIV-negative women 36 months after treatment by either ablation or excision. Bambury et al. [39] reported a recurrence rate of 66.2 cases per 100 person-years in HIV-positive women compared to 3.0 per 100 person-years in HIV-negative women following treatment by thermo-coagulation or LLETZ. The main attraction of ablative or excisional treatment after VIA/VILI is the opportunity to reduce or eliminate repeated clinic visits. However, these recurrence rates suggest that these treatments may not be effective in the long run particularly in HIV positive women who are at increased risk of persistent HPV infection. The paradigmatic "see and treat" approach may therefore be inadequate and women with VIA/VILI positive lesions may require long term follow up and treatment of recurrent lesions.

We also found that women who are 30 years of age or older had lower likelihood of recurrence. Previous studies of HIV-positive women show a steady decline in prevalence of VIA/VILI positive lesions with increasing age, most noticeable after age 30 years [6]. This may be a reflection of reduced prevalence of HPV infection with increasing age. Host immunity may also affect the likelihood of recurrence [40], so HIV-positive women may be at 
higher risk of recurrence than HIV-negative women. We found that severe immunosuppression, as marked by CD4 cell count of $<200 / \mathrm{mm}^{3}$ is associated with recurrence and this is consistent with the results of several studies of recurrence in HIV-positive women [35].

Our study provides some insight into the efficacy of thermo-coagulation treatment of VIA/VILI positive lesions in HIV-positive and HIV-negative African women and suggests a need for a review of screening policies on account of efficacy of treatment and risk of recurrence. HIV positive women with positive VIA/VILI positive lesions will require close long term follow up because of their higher risk of recurrence. The classical "see and treat" approach may be an insufficient screening strategy in this population because it may be associated with unacceptably high risk of recurrent lesions.

This study has limitations; it utilizes visual inspection (with Acetic acid and/or Lugol's Iodine) without cytological or histological diagnosis. Although validity of VIA/ VILI as method of screening for premalignant cervical lesions remains a subject of debate, a recent clinical trial by Huchko et al. [41] reveals that VIA/VILI provide acceptable results for cervical cancer screening in resourcepoor settings. However, to improve validity of test results our study employed a Quality Assurance/Quality Control (QA/QC) mechanism. We utilized a web-based cervicography with gynecologist verification in addition to on-site specialist reviews and peer review among nurses as QA/ QC methods, this process has previously been explained by Adebamowo et al [42]. Other limitations of this study include high rate of loss to follow up and short duration of follow up. It is possible that longer duration of follow up may reveal even higher recurrence in these women.

\section{Conclusion}

Recurrence of VIA or VILI positive lesions after thermocoagulation occurs in a significant proportion of women. HIV-positive women with low CD4 counts are at increased risk of recurrent lesions and may be related to immunosuppression.

More research on the efficacy of "see and treat" cervical cancer screening strategy is needed given the increasing adoption of VIA/VILI particularly as an adjunct to PEPFAR programs for HIV positive women.

\section{Ethics approval and consent to participate}

The study was reviewed and approved by the National Health Research Committee (NHREC) of Nigeria (NHREC Protocol Number: NHREC/01/01/2007-1909-2014, NHREC Approval Number: NHREC/01/01/ 2007-25/09/2014) and the Institutional Review Board (IRB) of the University of Maryland Baltimore (Reference number: HP-00061517).

\section{Consent for publication}

Not applicable.

\section{Availability of data}

The dataset(s) supporting the conclusions of this article are available upon request, please send requests to imanueloga@gmail.com.

\begin{abstract}
Abbreviations
CIN -: cervical intraepithelial neoplasia; HAART: highly active antiretroviral therapy; HIV: human immunodeficiency virus; VIA: visual inspection with acetic acid; VILI: visual inspection with Lugol's iodine.
\end{abstract}

\section{Competing interests}

The authors declare that they have no competing interests.

\section{Authors' contributions}

EAO drafted proposal and sought ethical approval, carried out data cleaning, data analysis and drafted the manuscript. JPB worked on proposal, ethical approval processes, data analysis and drafting of the manuscript. CB supervised proposal drafting, data analysis and drafting of the manuscript. ED worked on study implementation and data collection, data analysis and drafting the manuscript. MO supervised clinical data collection, assisted with data cleaning and drafting the manuscript. VA supervised clinical data collection and assisted with drafting the manuscript. OO supervised clinical data collection and assisted with drafting the manuscript. RO supervised clinical data collection and assisted with drafting the manuscript. KO supervised clinical data collection and assisted with drafting the manuscript. AS supervised clinical data collection and assisted with drafting the manuscript. AP supervised clinical data collection and assisted with drafting the manuscript. PD supervised study implementation and assisted with drafting the manuscript. CA conceived the study, supervised study implementation and data collection, participated in data analysis and drafting of the manuscript. All authors read and approved the final manuscript.

\section{Acknowledgement}

We thank George Odonye for assisting with database management, data collection and cleaning; Yinka Owoade for assistance with project implementation; Jesse James and Ruxton Adebiyi for data collection and cleaning; and Maryam Al-Mujtaba for study implementation.

\section{Funding}

The project described was supported by Grant Number D43CA153792-01 ( $\mathrm{PI}$ - Adebamowo) from the $\mathrm{NCl} / \mathrm{NIH}$. The content is solely the responsibility of the authors and does not necessarily represent the official views of the National Cancer Institute or the National Institutes of Health.

\section{Author details}

${ }^{1}$ Department of Epidemiology and Public Health, University of Maryland School of Medicine, Baltimore, MD 21201, USA. Institute of Human Virology Nigeria (IHVN), Abuja, Nigeria. ${ }^{3}$ National Hospital, Abuja, Nigeria. ${ }^{4}$ University of Abuja Teaching Hospital, Gwagwalada, Nigeria. ${ }^{5}$ Garki Hospital, Abuja, Nigeria. ${ }^{6}$ Mother and Child Hospital, Ondo, Nigeria. ${ }^{7}$ Federal Medical Centre, Keffi, Nigeria. ${ }^{8}$ University of Maryland Marlene and Stewart Greenebaum Cancer Center, Baltimore, MD, USA. ${ }^{9}$ Institute of Human Virology, University of Maryland School of Medicine, Baltimore, MD, USA. ${ }^{10}$ Department of Public Health and Primary Care, University of Cambridge, Cambridge, UK.

Received: 4 July 2015 Accepted: 4 May 2016

Published online: 11 May 2016

\section{References}

1. Ferlay J, Soerjomataram I, Ervik M, Dikshit R, Eser S, Mathers C, Rebelo M, Parkin DM, Forman D, Bray F. GLOBOCAN 2012 v1.0, Cancer Incidence and Mortality Worldwide: IARC CancerBase No. 11 [Internet]. Lyon: International Agency for Research on Cancer; 2013. Available from: http://globocan.iarc.fr. Accessed 9 Sept 2014 
2. Jia Y, Li S, Yang R, et al. Knowledge about cervical cancer and barriers of screening program among women in Wufeng County, a high-incidence region of cervical cancer in China. PLoS One. 2013;8(7):e67005.

3. Cronjé HS. Screening for cervical cancer in the developing world. Best Pract Res Clin Obstet Gynaecol. 2005;19(4):517-29.

4. Elovainio L, Nieminen P, Miller AB. Impact of cancer screening on women's health. Int J Gynaecol Obstet. 1997;58(1):137-47.

5. Denny L, Quinn M, Sankaranarayanan R. Chapter 8: Screening for cervical cancer in developing countries. Vaccine. 2006;24 Suppl 3:S3/71-7.

6. Ononogbu U, Almujtaba M, Modibbo F, et al. Cervical cancer risk factors among HIV-infected Nigerian women. BMC Public Health. 2013;13:582.

7. 1993 revised classification system for HIV infection and expanded surveillance case definition for AIDS among adolescents and adults. MMWR Recomm Rep. 1992;41(RR-17):1-19.

8. Denslow SA, Rositch AF, Firnhaber C, Ting J, Smith JS. Incidence and progression of cervical lesions in women with HIV: a systematic global review. Int J STD AIDS. 2014;25(3):163-77.

9. Franceschi $\mathrm{S}$, Jaffe $H$. Cervical cancer screening of women living with HIV infection: a must in the era of antiretroviral therapy. Clin Infect Dis. 2007:45(4):510-3.

10. Franceschi S, Herrero R, Clifford GM, et al. Variations in the age-specific curves of human papillomavirus prevalence in women worldwide. Int J Cancer. 2006;119(11):2677-84.

11. Parkin D, Ferlay J, Hamdi-Chérif M, et al. Cancer in Africa. In: Epidemiology and prevention. Lyon: IARC Press; 2003.

12. Jedy-Agba E, Curado MP, Ogunbiyi O, et al. Cancer incidence in Nigeria: a report from population-based cancer registries. Cancer Epidemiol. 2012;36(5):e271-8.

13. Organization WH. Global health observatory data repository: number of people (all ages) living with HIV. Geneva: WHO; 2013.

14. IARC. An Introduction to Cervical Intraepithelial Neoplasia (CIN). Colposcopy and Treatment of Cervical Intraepithelial Neoplasia: A Beginner's Manual IARC, 150 Cours Albert Thomas, 69372 Lyon CEDEX 08, France: IARC Scientific Publication; 2014:20.

15. Six C, Heard I, Bergeron C, et al. Comparative prevalence, incidence and short-term prognosis of cervical squamous intraepithelial lesions amongst HIV-positive and HIV-negative women. AIDS. 1998;12(9):1047-56.

16. Lindeque BG. Management of cervical premalignant lesions. Best Pract Res Clin Obstet Gynaecol. 2005;19(4):545-61.

17. Dolman L, Sauvaget C, Muwonge R, Sankaranarayanan R. Meta-analysis of the efficacy of cold coagulation as a treatment method for cervical intraepithelial neoplasia: a systematic review. BJOG. 2014;121(8):929-42.

18. Kocken M, Helmerhorst TJ, Berkhof J, et al. Risk of recurrent high-grade cervical intraepithelial neoplasia after successful treatment: a long-term multi-cohort study. Lancet Oncol. 2011;12(5):441-50.

19. Malapati R, Chaparala S, Cejtin HE. Factors influencing persistence or recurrence of cervical intraepithelial neoplasia after loop electrosurgical excision procedure. J Low Genit Tract Dis. 2011;15(3):177-9.

20. Reimers $L L$, Sotardi S, Daniel D, et al. Outcomes after an excisional procedure for cervical intraepithelial neoplasia in HIV-infected women. Gynecol Oncol. 2010;119(1):92-7.

21. Serati M, Siesto G, Carollo S, et al. Risk factors for cervical intraepithelial neoplasia recurrence after conization: a 10-year study. Eur J Obstet Gynecol Reprod Biol. 2012;165(1):86-90.

22. Boonlikit S, Junghuttakarnsatit P, Asavapiriyanont S. Treatment failure following large loop excision of the transformation zone for the treatment of cervical intraepithelial neoplasia at Rajavithi Hospital. J Med Assoc Thai. 2008;91(1):31-6.

23. Kjellberg L, Tavelin B. 'See and treat' regime by LEEP conisation is a safe and time saving procedure among women with cytological high-grade squamous intraepithelial lesion. Acta Obstet Gynecol Scand. 2007:86(9):1140-4.

24. Lima Ml, Tafuri A, Araújo AC, de Miranda Lima L, Melo VH. Cervical intraepithelial neoplasia recurrence after conization in HIV-positive and HIV-negative women. Int J Gynaecol Obstet. 2009;104(2):100-4.

25. Lodi CT, Michelin MA, Lima Ml, et al. Factors associated with recurrence of cervical intraepithelial neoplasia after conization in HIV-infected and noninfected women. Arch Gynecol Obstet. 2011;284(1):191-7.

26. Tebeu PM, Major AL, Mhawech P, Rapiti E. The recurrence of cervica intraepithelial neoplasia in HIV-positive women: a review of the literature. Int J STD AIDS. 2006;17(8):507-11.
27. Foulot H, Heard I, Potard V, Costagliola D, Chapron C. Surgical management of cervical intraepithelial neoplasia in HIV-infected women. Eur J Obstet Gynecol Reprod Biol. 2008;141(2):153-7.

28. Lu CH, Liu FS, Kuo CJ, Chang CC, Ho ES. Prediction of persistence or recurrence after conization for cervical intraepithelial neoplasia III. Obstet Gynecol. 2006;107(4):830-5.

29. Zivadinovic R, Lilic G, Lilic V, Petric A, Filipovic S, Todorovska I. Recurrence of cervical intraepithelial neoplasias with negative cone margins: risk factors. J BUON. 2011;16(3):498-504.

30. Adam Y, van Gelderen CJ, de Bruyn G, Mclntyre JA, Turton DA, Martinson NA. Predictors of persistent cytologic abnormalities after treatment of cervical intraepithelial neoplasia in Soweto, South Africa: a cohort study in a HIV high prevalence population. BMC Cancer. 2008:8(1):211.

31. Memiah P, Mbuthia W, Kiiru G, et al. Prevalence and risk factors associated with precancerous cervical cancer lesions among HIV-infected women in resource-limited settings. AIDS Res Treat. 2012;2012:953743.

32. Zeier MD, Nachega JB, Van Der Merwe FH, et al. Impact of timing of antiretroviral therapy initiation on survival of cervical squamous intraepithelial lesions: a cohort analysis from South Africa. Int J STD AIDS. 2012;23(12):890-6.

33. Sellors JW, Sankaranarayanan R. Colposcopy and treatment of cervical intraepithelial neoplasia: a beginner's manual. Diamond Pocket Books (P) Ltd.; 2003.

34. Duncan ID. Cold coagulation. Baillieres Clin Obstet Gynaecol. 1995;9(1):145-55.

35. Huchko MJ, Leslie H, Maloba M, Zakaras J, Bukusi E, Cohen CR. Outcomes up to Twelve Months after Treatment with Loop Electrosurgical Excision Procedure for Cervical Intraepithelial Neoplasia Among HIV-Infected Women. J Acquir Immune Defic Syndr (1999). 2015;69(2):200-5.

36. Heard I, Potard V, Foulot H, Chapron C, Costagliola D, Kazatchkine MD. High rate of recurrence of cervical intraepithelial neoplasia after surgery in HIV-positive women. J Acquir Immune Defic Syndr. 2005;39(4):412-8.

37. De Vuyst H, Mugo NR, Franceschi S, et al. Residual Disease and HPV Persistence after Cryotherapy for Cervical Intraepithelial Neoplasia Grade 2/3 in HIV-Positive Women in Kenya. PLoS One. 2014;9(10):e111037.

38. Fruchter RG, Maiman M, Sedlis A, Bartley L, Camilien L, Arrastia CD. Multiple recurrences of cervical intraepithelial neoplasia in women with the human immunodeficiency virus. Obstet Gynecol. 1996:87(3):338-44.

39. Bambury I, Mullings A, Fletcher H, Johnson N, Tulloch-Reid M. Cervical intraepithelial neoplasia in a cohort of HIV-positive women at the University Hospital of the West Indies: management and outcome. West Indian Med J. 2013;62(4):313-7.

40. Moscicki A-B, Schiffman $M$, Burchell $A$, et al. Updating the natural history of human papillomavirus and anogenital cancers. Vaccine. 2012;30:F24-33.

41. Huchko MJ, Sneden J, Zakaras JM, et al. A Randomized Trial Comparing the Diagnostic Accuracy of Visual Inspection with Acetic Acid to Visual Inspection with Lugol's lodine for Cervical Cancer Screening in HIV-Infected Women. PloS one. 2015;10(4):e0118568

42. Adebamowo C, Almujtaba M, Modibbo Z, Olaniyan O, Blattner W. Digital cervicography and cold coagulation for cervical cancer screening in Nigeria. Infect Agents Cancer. 2012;7 Suppl 1:14

\section{Submit your next manuscript to BioMed Central and we will help you at every step:}

- We accept pre-submission inquiries

- Our selector tool helps you to find the most relevant journal

- We provide round the clock customer support

- Convenient online submission

- Thorough peer review

- Inclusion in PubMed and all major indexing services

- Maximum visibility for your research

Submit your manuscript at www.biomedcentral.com/submit 